\title{
Erratum to: Farmers' perceptions of climate variability and barriers to adaptation: lessons learned from an exploratory study in Vietnam
}

\author{
Hoa Le Dang • Elton Li • Johan Bruwer • Ian Nuberg
}

Published online: 3 March 2013

(C) Springer Science+Business Media Dordrecht 2013

\section{Erratum to: Mitig Adapt Strateg Glob Change \\ DOI 10.1007/s11027-012-9447-6}

On several occasions, the words "climate variability" have been substituted for the words "climate change". However, the change of context does not reflect the authors views. The authors wish to reiterate that the term "climate change" was their intended interpretation.

The online version of the original article can be found at http://dx.doi.org/10.1007/s11027-012-9447-6.

H. Le Dang $(\bowtie) \cdot$ E. Li $\cdot$ J. Bruwer

School of Agriculture, Food and Wine, The University of Adelaide, Level 3, WIC building,

Waite Campus, Urrbrae, South Australia 5064, Australia

e-mail: danglehoa@yahoo.com

H. Le Dang

e-mail: le.dang@adelaide.edu.au

E. $\mathrm{Li}$

e-mail: elton.li@adelaide.edu.au

J. Bruwer

e-mail: johan.bruwer@adelaide.edu.au

H. Le Dang

Faculty of Economics, Nong Lam University, Linh Trung Ward, Thu Duc District,

Ho Chi Minh City, Vietnam

e-mail: danglehoa@hcmuaf.edu.vn

I. Nuberg

School of Agriculture, Food and Wine, The University of Adelaide, GN 10a, Waite main building, Waite Campus, Urrbrae, South Australia 5064, Australia

e-mail: ian.nuberg@adelaide.edu.au 